Teaching
Methods

\section{Comparing Student Performance in Live Versus Web-based Instruction in Herbaceous Plant Identification}

\author{
Igino Teolis ${ }^{1,3,4}$, Ellen B. Peffley ${ }^{1}$, and David B. Wester ${ }^{2}$
}

ADDITIONAL INDEX WORDS. computer, computer-assisted instruction, distance education, learning styles, horticulture education

SumMARY. A study was conducted to evaluate student performance after receiving the same horticultural lesson through one of two modes of instruction. Students enrolled in an introductory horticulture course received either a traditional herbaceous plant identification (ID) lesson with live plant specimens or the same lesson using only text and photographs on the Internet in one of their laboratory sessions. A follow-up experiment was conducted in which web-based students studied photographs of the exact same plants studied by students receiving traditional instruction. Learning style preferences and demographic information were obtained from surveys. For both experiments, students receiving traditional instruction had higher scores on the plant ID quiz than web-based students. All students were able to identify plants from photographs just as well as from live plant specimens. Visual learners scored higher when receiving traditional instruction when compared with web-based instruction. Student grade point average was positively correlated with quiz score for both experiments.

$\mathrm{P}$ lant identification is taught in horticulture and botany courses worldwide. Educators use visual tools to help students learn plant materials (Kling et al., 1996). Accessing live plant specimens to display variations in plant appearance at different growth stages and environments may be difficult (White et al.,

\footnotetext{
This article is a portion of a dissertation submitted by Igino Teolis in fulfilling the $\mathrm{PhD}$ requirement.

${ }^{1}$ Department of Plant and Soil Science, Texas Tech University, Box 42122, Lubbock, TX 79409-2122.

${ }^{2}$ Department of Range, Wildlife, and Fisheries Management, Texas Tech University, Box 42125, Lubbock, TX 79409-2125

${ }^{3}$ Current address: National Center on Institutions and Alternatives, 7130 Rutherford Rd., Baltimore, MD 21244.

${ }^{4}$ Corresponding author. E-mail: iginoteolis@hotmail.com
}

1990), and reference books may not provide adequate visual plant information (Kling et al., 1996). Obstacles to teaching plant identification include not having live plant material in season, limited time spent in the classroom or laboratory to view slides, and insufficient comparisons of pictures per taxon (White et al., 1990).

These constraints have been reduced through use of videodiscs and computers, in which students interact through questions and guided prompts (White et al., 1990). Computer-assisted instruction has been used to help students learn the morphologic relationships between plants and learn morphology to identify unknown species (Shaw, 1993). Computer-based systems can also store large numbers of visual images in a format that is compact and affordable (Kling et al., 1996).

Several software programs have been developed to help students identify plants (Kling et al., 1996; Peffley et al., 1999a; Pohl, 1989; Sabota et al., 1995; Seiler et al., 2002). With the advent of these computer aids, it would be of interest to examine whether these programs are as effective in assisting students in identifying plants as traditional (classroom or laboratory)-based instruction.

In a study conducted by Seiler et al. (2002), computer instruction was superior to live instruction in teaching plant identification. Students who used a woody plant identification software program for a 2 -week period increased their scores on weekly plant identification (ID) quizzes when compared with students receiving traditional review sessions with an instructor. In contrast, in each of three case studies, Taraban et al. (2004) reported higher plant ID quiz scores when students received live instruction on herbaceous or woody plants than when they received instruction through the web.

A few studies in plant identification have used photographs while testing students. Students obtained higher scores when completing plant ID tests involving photographs on the web when compared with taking tests in the laboratory with live plant specimens (Anderson and Walker, 2003). While offering an online tree identification class, Seiler et al. (2002) noted students were very successful in identifying tree species in previously unseen photographs on the computer. However, it is inconclusive from the literature as to whether web-based students can identify plants from photographs and live specimens on quizzes just as well as traditional course students.

Educators should be aware their students may represent a range of learning styles and that a learning sequence that is suitable for one student may not be suitable for another student (Bork and Gunnarsdottir, 2001). Therefore, teaching in such a manner that would satisfy all or most of those styles would increase learning in the classroom. Kahtz (2000) reported that supplementing a woody plant identification course with computer-assisted instruction 
was of equal benefit to field-dependent students (who take a "spectator" approach in learning and need more explicit instruction in solving problems) or field-independent students (who are more active by developing strategies to learn material lacking in structure) (Witkin et al., 1977). To better understand distance teaching and learning, research is needed on the relationship between learning styles and agricultural distance education (Miller, 1997). Such research was addressed in this study.

To achieve this goal, this study examined whether students obtained equivalent scores in a plant ID quiz after receiving live or web-based instruction in herbaceous plant identification. In addition, we investigated whether the two groups of students differed in identifying plants from live specimens and photographs, and examined whether learning style and demographic factors [age, gender, grade point average (GPA), level of computer use] were correlated to quiz scores for each mode of instruction.

\section{Materials and methods}

Participants. Participants consisted of students who were enrolled in the regular laboratory sections of Principles of Horticulture at Texas Tech University. One of the laboratory sessions focused on the identification of herbaceous plants.

Materials. Materials for this study included live samples and photographs of 20 herbaceous plant species. The live samples were used during live instruction. Both live samples and photographs were used for the plant ID quizzes. The TechHort web site (Peffley et al., 1999b) provided information on each of the species in text and pictures, including growth habit, size, foliage, inflorescence, and culture. Printed copies of the information from the web site were used for live instruction. A survey distributed to the students gathered background and demographic data, including their GPA. Included in the survey was a learning styles inventory (developed by B. Solomon, extracted from Carter et al., 1998). The inventory consisted of four "dimensions," each with two opposing styles: active/reflective, factual/ theoretical, visual/verbal, and linear/ holistic. Each student received a score from 7 to 14 for each of the four dimensions that indicated the student's preferred learning style for each dimension based on the student's responses on the inventory.

Procedure. The study was divided into two experiments. Expt. I was conducted in Spring 2001 and Expt. 2 was conducted in Fall 2001.

In Expt. 1, students in each of 12 laboratory sections were divided at random into two groups: web-based and traditional (live). Students assigned to the web-based group met in a computer laboratory for a brief orientation. They received verbal and written instructions on how to access and navigate through the TechHort web site. Students were told to study 16 herbaceous plants only on the computer and were allowed to ask questions of the teaching assistant (TA) during the week by telephone or e-mail but not in person (to simulate distance learning). Students in the traditional group met at the horticultural greenhouse on campus where they were each given typed instructions and a brief verbal explanation of the laboratory and proceeded to study the live plant material with the aid of the TA. Live plant material covered the same species that web-based students studied on the computer. To help ensure that the same information was presented to both the live and web-based groups, all TAs received copies of the information on the plants as displayed on the TechHort web site and were told to present the same material to the students in the live groups. Students in the traditional group were permitted to ask questions of the TA during the laboratory and the next week by telephone, e-mail, or in person. After 1 week, both groups within each laboratory section took the same quiz of 26 questions, half of which consisted of live plant material and the other half that consisted of photographs of plant material. Pictures were of the entire plant and closeup photographs of the leaf, flower (if present), and any distinguishable feature. A list of common names and scientific names of the plants studied were provided to the students. For each question, students had to write in the letter corresponding to the correct common name and the number corresponding to the correct scientific name. A few weeks after the quiz, all students were asked to complete the survey.

The procedure for Expt. 2 was the same as in Expt. I with one exception: photographs studied by web-based students were pictures of the same live plant specimens studied by the students in the traditional group. Seventeen herbaceous plants were used in Expt. 2.

Design and anAlysis. Only data from students who attended the orientation session in the web-based group or who were present at the greenhouse in the traditional group were included in the analysis. For both experiments, each laboratory section was treated as a block. A 2 (mode of instruction: traditional, web-based) $\times 2$ (question type: live specimen, photograph) factorial analysis of covariance, with GPA as the covariate, was conducted to determine whether students who received live or web-based instruction had higher scores on plant ID quizzes and whether students in one mode of instruction correctly identified more live plants or photographs. Analyses of variance were conducted to test whether gender was related to mode of instruction and whether students with the same learning style had different scores between each mode of instruction. Students were assigned to a particular learning style based on their score in the learning styles inventory. Correlation analyses were conducted to examine the relationship between quiz score and learning styles inventory scores, GPA, age, and the student's selfrating of computer use. The level of significance for all tests was set at 0.05 . Analyses were conducted using SAS (SAS Institute, Cary, N.C.)

\section{Results}

Expт. 1. For Expt. 1, 78 students received traditional instruction and 74 students received web-based instruction.

Students receiving traditional instruction had higher quiz scores than web-based students (Table 1). There was no effect on quiz scores by type of question (live specimen or photo) or mode of instruction $\times$ type of question interaction. There also was no effect on the quiz scores by gender $[\mathrm{F}(1,25)=$ 0.21 , nonsignificant] or mode of instruction $\times$ gender interaction $[\mathrm{F}(1,25)=0.82$, nonsignificant $]$. 
Table 1. Plant identification quiz scores (correct responses out of 13) according to mode of instruction, type of question, and mode of instruction/type of question combinations in Expt. 1 (Spring 2001). ${ }^{\mathrm{z}}$

\begin{tabular}{lcc}
\hline $\begin{array}{l}\text { Mode of instruction } \\
\text { (mean quiz score } \pm \mathrm{SE})\end{array}$ & $\begin{array}{c}\text { Type of question } \\
\text { (mean quiz score } \pm \mathrm{SE})\end{array}$ & $\begin{array}{c}\text { Mode of instruction/ } \\
\text { type of question } \\
\text { (mean quiz score } \pm \mathrm{SE} \text { ) }\end{array}$ \\
\hline Traditional & Live specimen & Traditional - live specimen \\
$10.12 \pm 0.40 \mathrm{a}$ & $9.32 \pm 0.34 \mathrm{a}$ & $10.27 \pm 0.47$ \\
Web-based & Photograph & Traditional - photograph \\
$8.40 \pm 0.42 \mathrm{~b}$ & $9.20 \pm 0.34 \mathrm{a}$ & $9.97 \pm 0.47$ \\
& & Web-based - photograph \\
& & $8.43 \pm 0.49$ \\
& & Web-based - live specimen \\
& & $8.38 \pm 0.49$ \\
\hline
\end{tabular}

${ }^{2}$ Means within a column followed by a common letter are not significantly different at the 0.05 level according to the analysis of covariance.

$\mathrm{SE}=$ standard error.

Correlation analysis between quiz scores and scores from the learning styles inventory revealed a significant negative correlation between quiz scores and scores for the factual/theoretical dimension (Table 2). Correlation coefficients were significant only for students in the traditional group.

When students with the same learning style were analyzed for quiz score, the only learning style for which there was a difference between instructional modes was the visual learning style (Table 3). Among students with the visual learning style, those receiving traditional instruction had higher quiz scores than webbased students.

Student GPA was positively correlated with quiz score for the traditional students (Table 4). There was no correlation between students' level of computer use (as indicated on the survey) or age with quiz score.

Expt. 2. For Expt. 2, 121 students received traditional and $109 \mathrm{stu}^{-}$ dents received web-based instruction.

Students in the traditional group had higher scores than web-based students (Table 5). Like in Expt. 1, there was no significant effect on quiz scores by type of question or mode of instruction $\times$ type of question interaction. Female students had higher total scores $(19.58 \pm 0.89)$ than males $(16.22 \pm 0.88)[\mathrm{F}(1,33)=12.99, P<$ $0.002]$. There was no significant mode of instruction $\times$ gender interaction $[\mathrm{F}(1,33)=0.24$, nonsignificant $]$.

Unlike Expt. 1, there was no correlation between total quiz scores and scores on the factual/theoretical dimension for traditional students. The only correlation obtained was a positive correlation between scores on the photograph portion of the quiz and scores on the active/reflective dimension for web-based students $[\mathrm{r}(103)=0.2167, P<0.03]$.

Like in Expt. 1, students in the traditional group had higher quiz scores than web-based students among students with a visual learning style $[\mathrm{F}(1,11)=4.99, P<0.05]$. In addition, students with an active learning style and receiving traditional instruction scored higher than active learners receiving web-based instruction $[\mathrm{F}(1,11)=8.77, P<0.02]$.

Grade point average was highly correlated with total quiz score for

Table 2. Pearson correlation coefficients of plant identification quiz scores with scores from the learning styles inventory in Expt. 1 (Spring 2001). ${ }^{\mathrm{z}}$

\begin{tabular}{|c|c|c|c|c|c|}
\hline \multirow[b]{2}{*}{ Quiz score } & \multirow[b]{2}{*}{$\begin{array}{c}\text { Mode of } \\
\text { instruction }\end{array}$} & \multicolumn{4}{|c|}{ Learning style dimension } \\
\hline & & $\begin{array}{l}\text { Active/ } \\
\text { reflective }\end{array}$ & $\begin{array}{c}\text { Factual/ } \\
\text { theoretical }\end{array}$ & $\begin{array}{c}\text { Visual/ } \\
\text { verbal }\end{array}$ & $\begin{array}{l}\text { Linear/ } \\
\text { holistic }\end{array}$ \\
\hline \multirow[t]{2}{*}{ Total score } & Traditional & $-0.0191^{\mathrm{Ns}}$ & $-0.3066^{* *}$ & $-0.0590^{\mathrm{Ns}}$ & $0.0627^{\mathrm{Ns}}$ \\
\hline & Web-based & $-0.0784^{\mathrm{Ns}}$ & $-0.1403^{\mathrm{Ns}}$ & $0.0170^{\mathrm{Ns}}$ & $-0.1162^{\mathrm{Ns}}$ \\
\hline \multirow{2}{*}{$\begin{array}{l}\text { Score from live specimen } \\
\text { portion of quiz }\end{array}$} & Traditional & $0.0164^{\mathrm{Ns}}$ & $-0.2830^{*}$ & $-0.0153^{\mathrm{NS}}$ & $-0.0715^{\mathrm{Ns}}$ \\
\hline & Web-based & $-0.1319^{\mathrm{Ns}}$ & $-0.0409^{\mathrm{Ns}}$ & $-0.0562^{\mathrm{Ns}}$ & $-0.0421^{\mathrm{Ns}}$ \\
\hline \multirow{2}{*}{$\begin{array}{l}\text { Score from photograph } \\
\text { portion of quiz }\end{array}$} & Traditional & $-0.0562^{\mathrm{Ns}}$ & $-0.2965^{*}$ & $-0.1003^{\mathrm{Ns}}$ & $0.0452^{\mathrm{NS}}$ \\
\hline & Web-based & $-0.0144^{\mathrm{Ns}}$ & $-0.2245^{\mathrm{Ns}}$ & $0.0893^{\mathrm{Ns}}$ & $-0.1775^{\mathrm{Ns}}$ \\
\hline
\end{tabular}

both traditional $[\mathrm{r}(71)=0.4603, P<$ $0.0001]$ and web-based students $[\mathrm{r}(59)=0.3567, P<0.006]$. A correlation between level of computer use or age with total quiz score was not found.

\section{Discussion}

Students receiving traditional instruction in each experiment had higher quiz scores than web-based students. This was not surprising, because Taraban et al. (2004) also reported higher scores among students receiving traditional instruction than web-based students when using similar materials. The study by Taraban et al. included similar plant species and the use of the same web site for the web-based students as did this study. It was believed that webbased students in Expt. I were at a disadvantage because plant specimens and photographs used in quizzes resembled more closely live plants studied by students in the traditional group than plants in photographs studied by web-based students. For this reason, photographs of plants studied by students in the traditional group were taken and put on the web for web-based students to study in Expt. 2. However, this did not increase quiz scores for web-based students in Expt. 2. In fact, the gap between scores of the two groups increased slightly for Expt. 2. As a result of the lack of correlation between level of computer use and quiz score, unfamiliarity with computers was probably not a factor in our study, similar to Taraban et al. (2004) and Pomar and Hidalgo (1998). A twodimensional picture simply may not be as good a teaching tool as a threedimensional object. Perhaps a lack of photographs of plants at different angles and closeup pictures of identifiable features may have contributed to lower scores of the web-based students. In addition, interaction with a live instructor could have helped the traditional group get the higher scores, suggesting that some live instruction would be a useful supplement to a web-based course.

It is possible that web-based students did not do as well on the quiz because they studied less than the traditional group. The amount of time spent studying for each participant was not recorded. In addition, the web-based students were allowed 
Table 3. Mean quiz scores (correct responses out of 26) for students grouped according to their learning styles and mode of instruction received in Expt. 1 (Spring 2001) with F values from testing for differences between modes of instruction. ${ }^{\mathrm{z}}$

\begin{tabular}{|c|c|c|c|c|}
\hline Learning style & Mode of instruction & $\mathbf{n}$ & $\begin{array}{c}\text { Mean quiz } \\
\text { score } \pm \text { SE }\end{array}$ & $\mathbf{F}$ \\
\hline \multirow[t]{2}{*}{ Active } & Traditional & 43 & $20.51 \pm 0.90$ & \multirow[t]{2}{*}{$4.85^{\mathrm{Ns}}$} \\
\hline & Web-based & 40 & $17.65 \pm 0.93$ & \\
\hline \multirow[t]{2}{*}{ Factual } & Traditional & 26 & $21.77 \pm 1.57$ & \multirow[t]{2}{*}{$4.15^{\mathrm{Ns}}$} \\
\hline & Web-based & 19 & $16.85 \pm 1.84$ & \\
\hline \multirow[t]{2}{*}{ Theoretical } & Traditional & 17 & $16.91 \pm 1.40$ & \multirow[t]{2}{*}{$0.04^{\mathrm{Ns}}$} \\
\hline & Web-based & 15 & $16.50 \pm 1.49$ & \\
\hline \multirow[t]{2}{*}{ Visual } & Traditional & 36 & $20.36 \pm 1.08$ & \multirow[t]{2}{*}{$6.60 *$} \\
\hline & Web-based & 39 & $16.48 \pm 1.05$ & \\
\hline \multirow[t]{2}{*}{ Verbal } & Traditional & 13 & $20.35 \pm 1.84$ & \multirow[t]{2}{*}{$1.85^{\mathrm{NS}}$} \\
\hline & Web-based & 7 & $15.64 \pm 2.93$ & \\
\hline \multirow[t]{2}{*}{ Linear } & Traditional & 34 & $20.19 \pm 1.04$ & \multirow[t]{2}{*}{$5.03^{\mathrm{NS}}$} \\
\hline & Web-based & 31 & $17.98 \pm 1.09$ & \\
\hline \multirow[t]{2}{*}{ Holistic } & Traditional & 5 & $21.00 \pm 2.26$ & \multirow[t]{2}{*}{$1.00^{\mathrm{NS}}$} \\
\hline & Web-based & 8 & $18.13 \pm 1.79$ & \\
\hline
\end{tabular}

${ }^{z}$ Analysis of variance was not conducted for the reflective learning style as a result of an insufficient number of students in this category.

ss, ${ }^{*}$ Nonsignificant or significant at $P=0.05$, respectively

$\mathrm{SE}=$ standard error.

to leave the computer laboratory after the orientation session, whereas students in the traditional group stayed in the greenhouse to listen to the TA's presentation of the material. In one of the case studies by Taraban et al. (2004), the web group actually reported longer study times than the live instruction group but still received lower scores on the quiz. Consequently, study time was not a factor in their experiment. that photographs are not as effective as live specimens in teaching plant identification, it does support the suggestion by Pokorny (1988) that quality color photographs may be as useful as live specimens for testing purposes, because the type of question (live specimen vs. photograph) had no effect on quiz score. These results are in contrast to those obtained by Anderson and Walker (2003), in which students had higher scores by looking at photographs on
Although this research suggests

the computer $(93.8 \%)$ than by looking at live plant specimens $(72.2 \%)$. However, because a majority of the participants (94\%) completed the web-based tests after completing the live plant ID tests and the web-based tests were not proctored, that study may have been biased in favor of higher web-based scores.

In our study, students who received traditional instruction had higher quiz scores on both the live plant specimen and photograph portions of plant ID quizzes as they preferred more of a factual learning style. Although the correlation between quiz scores and scores on the factual/theoretical dimension were only significant in Expt. 1, a similar trend was evident in Expt. 2. Factual learners prefer learning actual facts and data, are patient with details, like to follow the same procedure consistently, and are good at memorizing (Carter et al., 1998). Factual learners would be expected to do well on the

Table 4. Pearson correlation coefficients of plant identification quiz scores with student grade point average (GPA), level of computer use, and age in Expt. 1 (Spring 2001).

\begin{tabular}{lccc}
\hline Variable & Mode of instruction & $\mathbf{n}$ & $\mathbf{r}$ \\
\hline GPA & Traditional & 69 & $0.4462^{* *}$ \\
& Web-based & 68 & $0.1829^{\mathrm{Ns}}$ \\
Level of computer use & Traditional & 71 & $-0.1540^{\mathrm{Ns}}$ \\
& Web-based & 70 & $0.1195^{\mathrm{Ns}}$ \\
Age & Traditional & 71 & $-0.0816^{\mathrm{Ns}}$ \\
& Web-based & 69 & $-0.0964^{\mathrm{Ns}}$ \\
\hline
\end{tabular}

Ns, ${ }^{* *}$ Nonsignificant or significant at $P=0.01$, respectively. plant ID quiz, because the lesson requires learning details to differentiate the plants and memorization of plant features and common and scientific names. Why web-based students did not have a similar significant correlation is unclear. In contrast to factual learners, theoretical learners tend to prefer new concepts, theories, and big-picture ideas (Carter et al., 1998). Although scores on the active/reflective dimension for web-based students were significantly correlated with scores in the photograph portion of the quiz in Expt. 2 (the more reflective the learning style, the higher the quiz score), this trend was not consistent for both experiments and may have been the result of chance.

Moyles and Newell (1982) suggest the computer is an excellent tool for the visual learner. However, because there was not a significant correlation between quiz scores and scores on the visual/verbal learning style dimension, our study did not support their statement. In fact, when only visual learners were analyzed, webbased students obtained lower scores than students in the traditional group.

Distance education has been found to be more suitable for persons with certain characteristics. These include people with a higher level of maturity (Souder, 1993), those with an introverted nature (Biner et al., 1995), and persons with an auditory learning style (Oxford et al., 1993). In this study, quiz scores were positively correlated with student GPA, but there was no correlation between quiz score and the student's own rating of level of use on the computer for web-based students. Perhaps this suggests the TechHort web site used in this study was simple to use.

One potential limitation of this study is that students were tested on material presented in one lesson of a general horticulture course. The study would have been stronger and more significant differences possibly would have been obtained if student scores were obtained over several quizzes or over an entire plant identification course. In addition, the test was a matching quiz in which common and scientific names were provided, whereas most students in plant ID quizzes are required to write out the names. It is reasonable to infer that quiz scores would have been lower if students had to write the 
Table 5. Plant identification quiz scores (correct responses out of 13) according to mode of instruction, type of question, and mode of instruction/type of question combinations in Expt. 2 (Fall 2001). ${ }^{\mathrm{z}}$

\begin{tabular}{lcc}
\hline $\begin{array}{l}\text { Mode of instruction } \\
\text { (mean quiz score } \pm \mathrm{SE} \text { ) }\end{array}$ & $\begin{array}{c}\text { Type of question } \\
\text { (mean quiz score } \pm \mathrm{SE} \text { ) }\end{array}$ & $\begin{array}{c}\text { Mode of instruction/ } \\
\text { type of question } \\
\text { (mean quiz score } \pm \mathrm{SE} \text { ) }\end{array}$ \\
\hline Traditional & Live specimen & Traditional - live specimen \\
$10.21 \pm 0.32 \mathrm{a}$ & $9.54 \pm 0.33 \mathrm{a}$ & $10.56 \pm 0.41$ \\
Web-based & Photograph & Traditional - photograph \\
$8.34 \pm 0.34 \mathrm{~b}$ & $9.01 \pm 0.33 \mathrm{a}$ & $9.87 \pm 0.41$ \\
& & Web-based - live specimen \\
& & $8.53 \pm 0.44$ \\
& & Web-based - photograph \\
& & $8.16 \pm 0.44$ \\
\hline
\end{tabular}

${ }^{\mathrm{z}}$ Means within a column followed by a common letter are not significantly different at the 0.05 level, according to the analysis of covariance.

$\mathrm{SE}=$ standard error.

botanical names, but there is nothing to suggest that this would favor students in one mode of instruction over the other. Students in both the web and traditional groups received the same list of common and scientific names in their handout to study.

Regardless of the mode of instruction, the mean quiz scores were low (always less than 80\%). Methods to improve overall quiz scores may include giving the students a sample quiz so that they can have better idea of what to expect on the actual quiz. Students in the traditional group may be required to remain in the greenhouse to study the plants for the full 2 -hour duration of the laboratory session instead of being allowed to leave after the TA's instruction. If computer $\log$-ins could be monitored, web-based students may be required to $\log$ in for at least a certain amount of time. The quiz may also make up a more significant portion of the final course grade. At the time of this study, the herbaceous plant ID quiz made up less than $5 \%$ of the final course grade.

Assuming that both groups of students were equally exposed to the subject matter, this study suggests that students do not retain as much information through web-based instruction as through traditional live instruction in plant identification. Within each mode of instruction, students can identify plants from photographs with the same accuracy as from live plant specimens. Distance learning may be improved by including a greater variety of photographs that illustrate the appearance of the plant at different times in the growing season. More closeup photographs of the features useful in identifying the species may be included. Distance education students may be encouraged to visit a botanic garden, nursery, or similar location where they can get some "hands-on" experience with plants. Communication between the student and the instructor in a web-based course should be easily available and questions should be encouraged with immediate feedback from the instructor.

\section{Literature cited}

Anderson, N.O. and J.D. Walker. 2003. Effectiveness of web-based versus live plant identification tests. HortTechnology 13:199-205.

Biner, P.M., M.L. Blink, M.L. Huffman, and R.S. Dean. 1995. Personality characteristics differentiating and predicting the achievement of televised-course students and traditional-course students. Am. J. Distance Educ. 9(2):46-60.

Bork, A. and S. Gunnarsdottir. 2001. Tutorial distance learning: Rebuilding our educational system. Kluwer Academic Publishers. N.Y.

Carter, C., J. Bishop, and S.L. Kravits. 1998. Keys to success: How to achieve your goals, 2 nd ed. Prentice-Hall, Upper Saddle River, N.J.

Kahtz, A.W. 2000. Can computerassisted instruction be used by students for woody plant identification? HortTechnology 10:381-384.

Kling, G.J., C.P. Lindsey, and M.E. Zampardo. 1996. UIPLANTS: A software program for the landscape industry and horticulture education. HortTechnology 6:337-343.

Miller, G. 1997. Cognitive style preferences of agricultural distant learners. Natl. Assn. Colleges Teachers Agr. J. 41(4):23-28.
Moyles, L.C. and J. Newell. 1982. Microcomputers in a postsecondary curriculum. Academic Therapy 18:149-155.

Oxford, R., Y. Park-Oh, S. Ito, and M. Sumrall. 1993. Factors affecting achievement in a satellite-delivered Japanese language program. Amer. J. Distance Educ. $7(1): 11-25$.

Peffley, E.B., R.E. Durham, and C.B. McKenney. 1999a. TechHort: The art of plant science (companion to Principles of Horticulture). CD-ROM. Texas Tech University, Lubbock.

Peffley, E.B., R.E. Durham, and C.B. McKenney. 1999b. TechHort horticulture: The art of plant science. 8 Sept. 2006. $<$ http://www.pssc.ttu.edu/TechHort/>.

Pohl, D. 1989. Plant Locator-A computer program to promote learning plant identification. Natl. Assn. Colleges Teachers Agr. J. 33(1):43-45.

Pokorny, F.A. 1988. Computer-assisted plant identification tests. Natl. Assn. Colleges Teachers Agr. J. 32(2):28-30.

Pomar, J. and I. Hidalgo. 1998. An intelligent multimedia system for identification of weed seedlings. Computers Electronics Agr. 19:249-264.

Sabota, C., C.A. Beyl, and G. Ghale. 1995. Developing an integrated location and information database for teaching plant identification and use. HortTechnology 5:178-182.

Seiler, J.R., O. Popescu, and J.A. Peterson. 2002. A woody plant identification tutorial improves field identification skills. J. Natural Resources Life Sci. Educ. 31:12-15.

Shaw, P.M. 1993. A low-cost interactive computer program for teaching landscape plant materials. HortTechnology 3:351-354.

Souder, W.E. 1993. The effectiveness of traditional vs. satellite delivery in three management of technology master's degree programs. Amer. J. Distance Educ. 7(1):37-53.

Taraban, R., C. McKenney, E. Peffley, and A. Applegarth. 2004. Live specimens more effective than World Wide Web for learning plant material. J. Natural Resources Life Sci. Educ. 33:106-110.

White, J.W., D.J. Beattie, and P. Kubek. 1990. Inquiry learning with videodiscs and computers: An innovative teaching method for horticulture courses. HortScience 25:385-388.

Witkin, H.A., C.A. Moore, D.R. Goodenough, and P.W. Cox. 1977. Field-dependent and field-independent cognitive styles and their educational implications. Rev. Educ. Res. 47:1-64. 